Research Article

\title{
Dynamic Analysis of a Tapered Composite Thin-Walled Rotating Shaft Embedded with SMA Wires Using the Generalized Differential Quadrature Method
}

\author{
Weiyan Zhong, Feng Gao $\left(D\right.$, Yongsheng Ren ${ }^{D}$, Xiaoxiao Wu, and Hongcan Ma \\ College of Mechanical and Electronic Engineering, Shandong University of Science and Technology, Qingdao 266590, China \\ Correspondence should be addressed to Feng Gao; jdgaofeng@163.com
}

Received 23 February 2020; Revised 18 August 2020; Accepted 26 August 2020; Published 10 September 2020

Academic Editor: Giuseppe Petrone

Copyright ( $\odot 2020$ Weiyan Zhong et al. This is an open access article distributed under the Creative Commons Attribution License, which permits unrestricted use, distribution, and reproduction in any medium, provided the original work is properly cited.

\begin{abstract}
A dynamical model is developed for the tapered composite thin-walled rotating shaft with shape memory alloy (SMA) wires embedded in. The SMA wires are embedded at an interlayer of the shaft and arranged along the conical surface of the tapered composite shaft. Recovery stresses generated during the phase transformation are calculated based on one-dimensional Brinson's model. The governing equations are obtained based on a refined variational asymptotic method (VAM) and Hamilton's principle. The partial differential equations of motion are reduced to the ordinary differential governing equations by using the generalized differential quadrature method (GDQM). Numerical results of natural frequencies and critical speeds are obtained. The effects of the fraction of SMA wires, the initial strain of SMA wires, temperature, ply angle, taper ratio, boundary conditions, and rotating speed on the frequency characteristics are investigated.
\end{abstract}

\section{Introduction}

Composite materials have found numerous applications in many engineering fields thanks to high specific strength and high specific stiffness compared to metals and metallic alloys. A composite shaft gives higher frequencies, higher critical speeds, and lower vibration compared with conventional metallic shaft. The shaft becomes lightweight structure when it is tapered. Several authors have put their focus on the development of tapered shaft rotors. Kim et al. [1-4] developed a dynamic model on tapered composite Timoshenko shaft which runs around its axis at a constant speed. In their study, the vibration analysis of the tapered shaft was carried out using the general Galerkin method. Na et al. [5] studied the vibration and stability of a cylindrical shaft modeled as a tapered thinwalled composite beam and adopted the extended Galerkin method to solve the eigenvalue problem. Ma et al. [6] studied the free vibration characteristics and stability of variable cross section composite shaft for cantilever boundary condition and also used the Galerkin method to discretize and solve the governing equations. Rachid et al. [7] proposed a theoretical and numerical study on the behavior of a tapered shaft rotor made of composite materials by the classical version $h$ and the version $\mathrm{p}$ of the finite element method. Almuslmani and Ganesan [8] utilized hierarchical finite element method (HFEM) to perform rotodynamic analysis on tapered composite shaft. Zhong et al. [9] studied the natural frequencies and critical rotating speeds of the tapered composite shaft with different boundary conditions using the generalized differential quadrature method.

By employment of composite materials and intelligent materials simultaneously, the structures with unique properties can be achieved. The demand for intelligent materials which are sensitive to the environment is increasing. Compared with other smart materials, shape memory alloy (SMA) has the unique property of large recoverable strain. The SMA composites are a new class of smart materials capable of changing both their stiffnesses and their elastic properties. The stiffness modification occurs as a result of 
thermally induced martensite phase transformation of SMA fibers embedded in composite structures. Some studies have been done to build smart composite shafts by combining the advantages of both the composite material and the SMA. Baz and Chen [10] analyzed a composite rotor embedded with Nitinol wires by theoretical and experimental means. Their results showed that activating Nitinol wires results in a reduction of about $50 \%$ in vibration amplitudes. Gupta [11] investigated the combined effect of embedding the SMA wires in a rotor shaft and change of support stiffness using the SMA on rotor critical speeds. Sawhney and Jain [12] carried out fabrication and experimental investigations on the fiber-reinforced composite shaft embedded with the SMA wires. Baz and Chen [13] studied the static and thermal characteristics of SMA-reinforced composite drive shafts. They found that the Nitinol wires can play a role in enhancing the torsional stiffness. Tylikowski [14] studied the dynamic stability of the activated shape memory alloy hybrid cylindrical shells consisting of symmetrical balanced angle-ply laminated classical plies and symmetrically laminated active plies with axially oriented SMA fibers. Their results indicated that the global activation increased the admissible angular velocity. Tylikowski and Hetnarski [15] analyzed the stability criterion of the shaft equilibrium. The shaft was treated as a thin symmetrically laminated shell containing both the conventional fibers and the activated SMA fibers. The influence of SMA activation on stability regions was examined, and the results indicated that the SMA activation significantly increases the stability domains of the shaft. Gupta et al. [16] designed an experimental setup to embed prestressed SMA wires in the fiber-reinforced composite shaft. Experimental results showed the natural frequency of the composite shaft increased obviously due to activation of SMA wires. Ren et al. [17] developed a dynamical model for the rotating composite shaft with SMA wires embedded in and studied dynamical behavior of the shaft for simply supported at the ends using the Galerkin method to discretize and solve the governing equations. Murugesan et al. [18] experimentally measured the first natural frequency, damping time, and damping ratio for Carbon Fiber-Reinforced Plastic (CFRP) hollow shaft at both ends clamped end condition.

This paper studied the dynamical behavior of a tapered composite thin-walled rotating shaft embedded with SMA wires using a refined variational asymptotic method (VAM) and Hamilton's principle. To determine the tapered composite rotating shaft's dynamical characteristics, the GDQM is carried out here to approximate the governing differential equations of the shaft. The natural frequencies and critical rotating speeds of the tapered composite thin-walled rotating shaft with various boundary conditions are calculated. Finally, the influence of SMA activation on dynamical behaviors of the tapered composite rotating shaft has been investigated.

\section{Model of Tapered Composite Thin-Walled Rotating Shaft Embedded with SMA Wires}

The model of a tapered composite thin-walled rotating shaft with SMA wires is shown in Figure 1. The shaft rotates along its longitudinal $x$-axis at a constant angular velocity $\Omega$. The length, thickness, radius of curvature of root middle surface and radius of curvature of tip middle surface of the composite shaft are presented with $L, h, r_{R}$, and $r_{T}$, respectively. As seen in Figure $1,(X, Y, Z)$ represents the inertial reference system $(x, y, z)$ is the rotating reference system, and $(x, s, \xi)$ is the local coordinate system. The reference systems $(X, Y, Z)$ and $(x, y, z)$ have the common origin $O$ at the geometric center and the corresponding unit vectors are $(I, J$, $K)$ and $(i, j, k)$, respectively.

The SMA wires are embedded at an interlayer of the shaft and arranged along the conical surface of the tapered composite thin-walled rotating shaft.

The linear distribution along the tapered shaft of the radius of curvature of the mid-line cross sections $r(\zeta)$ varies according to the relationship [5]:

$$
r(\zeta)=[1-\zeta(1-\sigma)] r_{R}
$$

where $\sigma=r_{T} / r_{R}$ denotes the taper ratio and $\zeta=x / L$ $(0 \leq \zeta \leq 1)$ is the dimensionless cross section coordinate.

\section{Governing Equations}

3.1. Strain Energy and Kinetic Energy of the Composite Rotating ShaftEmbedded with SMA Wires. Based on the refined VAM thin-walled beam theory, the displacement function of the composite shaft is defined by [19]

$$
\begin{aligned}
u(x, y, z, t) & =u_{0}(x, t)-y(s) \varphi_{y}(x, t)-z(s) \varphi_{z}(x, t)+g(s, x, t), \\
v(x, y, z, t) & =v_{0}(x, t)-z(s) \phi(x, t), \\
w(x, y, z, t) & =w_{0}(x, t)+y(s) \phi(x, t),
\end{aligned}
$$

where $u_{0}(x, t), v_{0}(x, t)$, and $w_{0}(x, t)$ are the rigid body displacements along the $x^{-}, y^{-}$, and $z$-axis and $\varphi_{y}(x, t)$, $\varphi_{z}(x, t)$, and $\phi(x, t)$ are the rotations about $y$ - and $z$-axis and twist about $x$-axis, respectively. The expressions of $\varphi_{y}(x, t)$ and $\varphi_{z}(x, t)$ are

$$
\begin{aligned}
& \varphi_{y}(x, t)=v_{0}^{\prime}(x, t)-2 \gamma_{z x}, \\
& \varphi_{z}(x, t)=w_{0}^{\prime}(x, t)-2 \gamma_{y x},
\end{aligned}
$$

in which $\gamma_{z x}$ and $\gamma_{y x}$ are the transverse shear strains in the planes $x z$ and $x y$, respectively.

The warping displacement function $g(s, x, t)$ can be modified as [20]

$$
\begin{aligned}
g(s, x, t)= & G(s) \phi^{\prime}(x, t)+g_{1}(s) u_{0}^{\prime}(x, t)+g_{2}(s) \varphi_{y}^{\prime}(x, t) \\
& +g_{3}(s) \varphi_{z}^{\prime}(x, t),
\end{aligned}
$$




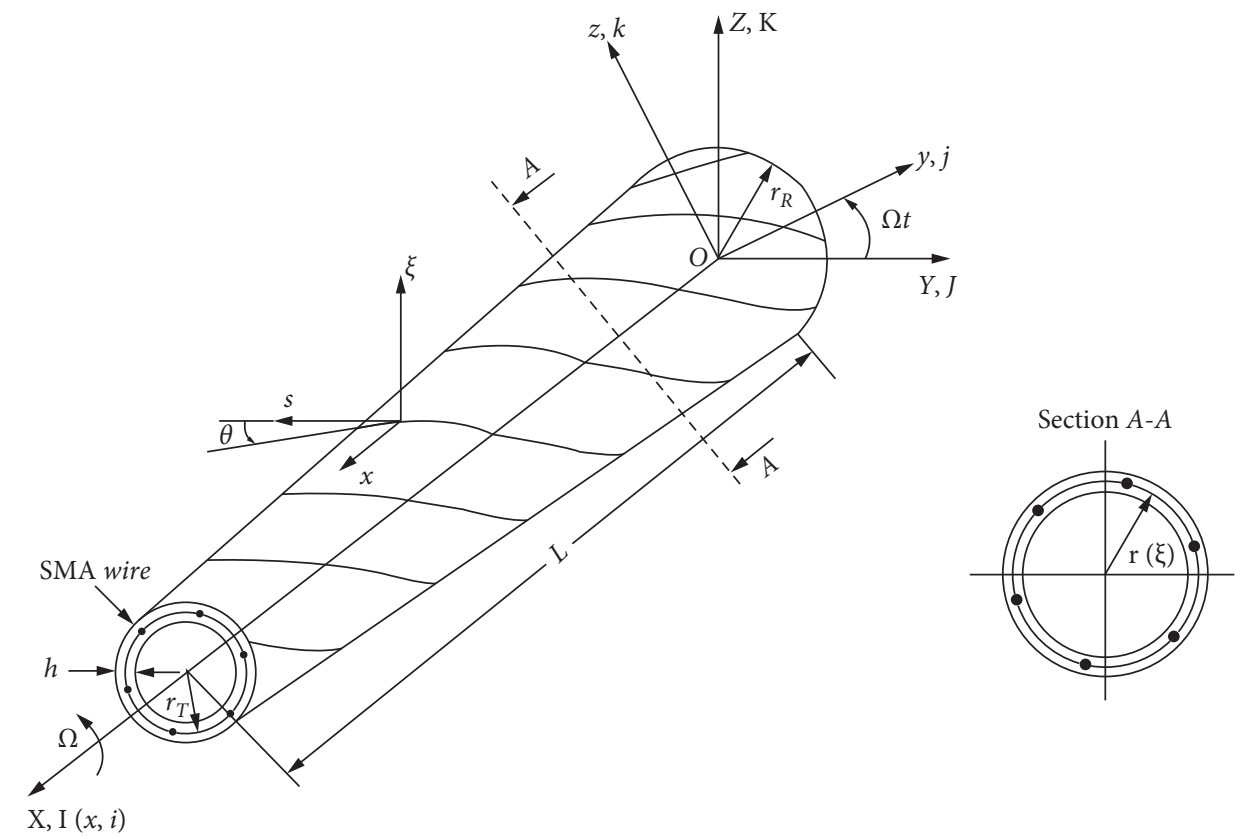

FIGURE 1: Coordinate systems and geometry of a tapered composite thin-walled rotating shaft with SMA wires.

where $G(s), g_{1}(s), g_{2}(s)$, and $g_{3}(s)$ are related to physical behavior of the torsion twist rate, the axial strain, and the bending curvatures, respectively.
According to equations (2), (3), and (4), the strains of the composite shaft are written as

$$
\begin{aligned}
\varepsilon_{x x} & =u_{0}^{\prime}(x, t)-y(s) \varphi_{y}^{\prime}(x, t)-z(s) \varphi_{z}^{\prime}(x, t), \\
2 \gamma_{x s} & =\frac{\mathrm{d} g(s, x, t)}{\mathrm{d} s}+r_{n}(s) \phi^{\prime}(x, t)+\left(v_{0}^{\prime}(x, t)-\varphi_{y}(x, t)\right) \frac{\mathrm{d} y}{\mathrm{~d} s}+\left(w_{0}^{\prime}(x, t)-\varphi_{z}(x, t)\right) \frac{\mathrm{d} z}{\mathrm{~d} s}, \\
2 \gamma_{x \xi} & =\left(v_{0}^{\prime}(x, t)-\varphi_{y}(x, t)\right) \frac{\mathrm{d} z}{\mathrm{~d} s}-\left(w_{0}^{\prime}(x, t)-\varphi_{z}(x, t)\right) \frac{\mathrm{d} y}{\mathrm{~d} s},
\end{aligned}
$$

where $r_{n}$ denotes the normal projection of $\mathbf{r}$ which is the position vector of an arbitrary point on the cross section of the deformed shaft and $r_{n}$ can be expressed as

$$
r_{n}=y(s) \frac{\mathrm{d} z(s)}{\mathrm{d} s}-z(s) \frac{\mathrm{d} y(s)}{\mathrm{d} s} .
$$

The position vector $\mathbf{r}$ can be written as

$$
\mathbf{r}=(y+v) i+(z+w) j+(x+u) k .
$$

Considering the assumption of constant rotating rate and taking the time derivatives of unit vectors, the velocity of an arbitrary point can be obtained as

$$
\dot{\mathbf{r}}=(\dot{v}-\Omega(z+w)) i+(\dot{w}+\Omega(y+v)) j+\dot{u} k .
$$

The kinetic energy of the composite rotating shaft $T$ can be written as

$$
T=\frac{1}{2} \int_{0}^{L} \iint_{A} \rho(\dot{\mathbf{r}} \cdot \dot{\mathbf{r}}) \mathrm{d} A \mathrm{~d} x .
$$

The strain energy of the composite shaft $U_{1}$ can be expressed as

$$
U_{1}=\frac{1}{2} \int_{0}^{L} \iint_{A}\left(\sigma_{x x} \varepsilon_{x x}+\tau_{x s} \gamma_{x s}+\tau_{x \xi} \gamma_{x \xi}\right) \mathrm{d} A \mathrm{~d} x,
$$

where $\sigma_{x x}, \tau_{x s}$, and $\tau_{x \xi}$ represent the cross section normal stress, in-plane shear stress, and transverse shear stress, respectively. And $\varepsilon_{x x}, \gamma_{x s}$, and $\gamma_{x \xi}$ are associated engineering strains.

The strain energy of SMA wires $U_{2}$ can be written as

$$
U_{2}=\frac{1}{2} \int_{0}^{L}\left(N^{\mathrm{SMA}}-N^{\Delta T}\right)\left(v_{0}^{\prime}\right)^{2} \mathrm{~d} x+\frac{1}{2} \int_{0}^{L}\left(N^{\mathrm{SMA}}-N^{\Delta T}\right)\left(w_{0}^{\prime}\right)^{2} \mathrm{~d} x,
$$

where $N^{\mathrm{SMA}}$ and $N^{\Delta T}$ denote the axial tension generated by SMA wires activation and thermal expansion, respectively.

Thus, the total strain energy $U$ is expressed as

$$
U=U_{1}+U_{2} .
$$


3.2. Governing Equations. The governing equations of the composite rotating shaft embedded with SMA wires can be derived based on Hamilton's principle, which is of the following form:

$$
\int_{t_{0}}^{t_{1}}(\delta U-\delta T) \mathrm{d} t=0
$$

In present study, a special ply-angle distribution referred to as circumferentially uniform stiffness (CUS) configuration [21] is considered. By employing Hamilton's principle and taking into account the variable cross section of the tapered shaft, the motion equations involving CUS configuration bending-transverse shear coupling are obtained as

$$
\begin{aligned}
& -C_{35}(x) \varphi_{z}^{\prime \prime}-C_{55}(x)\left(v_{0}^{\prime \prime}-\varphi_{y}^{\prime}\right)+\left(N^{\mathrm{SMA}}-N^{\Delta T}\right) v_{0}^{\prime \prime}+m_{c}\left(\ddot{v}_{0}-2 \Omega \dot{w}_{0}-\Omega^{2} v_{0}\right)=0, \\
& -C_{46}(x) \varphi_{y}^{\prime \prime}-C_{66}(x)\left(w_{0}^{\prime \prime}-\varphi_{z}^{\prime}\right)+\left(N^{\mathrm{SMA}}-N^{\Delta T}\right) w_{0}^{\prime \prime}+m_{c}\left(\ddot{w}_{0}+2 \Omega \dot{v}_{0}-\Omega^{2} w\right)=0, \\
& -C_{44}(x) \varphi_{y}^{\prime \prime}-C_{46}(x)\left(w_{0}^{\prime \prime}-\varphi_{z}^{\prime}\right)-C_{35}(x) \varphi_{z}^{\prime}-C_{55}(x)\left(v_{0}^{\prime}-\varphi_{y}\right)-I_{z} \ddot{\varphi}_{y}=0, \\
& -C_{33}(x) \varphi_{z}^{\prime \prime}-C_{35}(x)\left(v_{0}^{\prime \prime}-\varphi_{y}^{\prime}\right)-C_{46}(x) \varphi_{y}^{\prime}-C_{66}(x)\left(w_{0}^{\prime}-\varphi_{z}\right)-I_{y} \ddot{\varphi}_{z}=0,
\end{aligned}
$$

in which

$$
\begin{aligned}
& C_{33}(x)=\oint_{\Gamma(x)}\left(A-\frac{B^{2}}{C}\right) z^{2} \mathrm{~d} s+\left\{\frac{\left[\oint_{\Gamma(x)}(B / C) z \mathrm{~d} s\right]^{2}}{\oint_{\Gamma(x)}(1 / C) \mathrm{d} s}\right\}, \\
& C_{35}(x)=-\frac{1}{2} \oint_{\Gamma(x)} B z \frac{\mathrm{d} y}{\mathrm{~d} s} \mathrm{~d} s \\
& C_{44}(x)=\kappa \oint_{\Gamma(x)}\left(A-\frac{B^{2}}{C}\right) y^{2} \mathrm{~d} s+\left\{\frac{\left[\oint_{\Gamma(x)}(B / C) y \mathrm{~d} s\right]^{2}}{\oint_{\Gamma(x)}(1 / C) \mathrm{d} s}\right\}, \\
& C_{46}(x)=-\frac{1}{2} \kappa \oint_{\Gamma(x)} B y \frac{\mathrm{d} z}{\mathrm{~d} s} \mathrm{~d} s, \\
& C_{55}(x)=\kappa \oint_{\Gamma(x)}\left[\frac{1}{4} C\left(\frac{\mathrm{d} y}{\mathrm{~d} s}\right)^{2}+D\left(\frac{\mathrm{d} z}{\mathrm{~d} s}\right)^{2}\right] \mathrm{d} s \\
& C_{66}(x)=\kappa \oint_{\Gamma(x)}\left[\frac{1}{4} C\left(\frac{\mathrm{d} z}{\mathrm{~d} s}\right)^{2}+D\left(\frac{\mathrm{d} y}{\mathrm{~d} s}\right)^{2}\right] \mathrm{d} s,
\end{aligned}
$$

where

$$
\begin{aligned}
A & =\bar{A}_{11}-\frac{\left(\bar{A}_{12}\right)^{2}}{\bar{A}_{22}}, \\
B & =2\left[\bar{A}_{16}-\frac{\bar{A}_{12} \bar{A}_{26}}{\bar{A}_{22}}\right], \\
C & =4\left[\bar{A}_{66}-\frac{\left(\bar{A}_{26}\right)^{2}}{\bar{A}_{22}}\right], \\
D & =\left[\bar{A}_{44}-\frac{\left(\bar{A}_{45}\right)^{2}}{\bar{A}_{55}}\right], \\
\bar{A}_{i j} & =\sum_{k=1}^{N} \bar{Q}_{i j}^{k}\left(z_{k}-z_{k-1}\right), \quad(i, j=1,2,6 ; i, j=4,5) .
\end{aligned}
$$

Parameters $A$ and $B$ denote the reduced axial and coupling stiffness and parameters $C$ and $D$ represent the reduced shear stiffness, $\bar{A}_{i j}$ is the local stretching stiffness, $N$ is layer numbers, and $\bar{Q}_{i j}^{k}$ and $\left(z_{k}-z_{k-1}\right)$ represent the transformed stiffness and thickness of the $k$ th layer. $k$ is shear factor of the cross section which changes with the cross section and material properties, which is given by [1]

$$
\kappa=\frac{6 E_{x x}\left(1-\bar{m}^{4}\right)\left(1+\bar{m}^{2}\right)}{G_{x y} v_{x y}\left(2 \bar{m}^{6}+18 \bar{m}^{4}-18 \bar{m}^{2}-2\right)-E_{x x}\left(7 \bar{m}^{6}+27 \bar{m}^{4}-27 \bar{m}^{2}-7\right)},
$$

where $\bar{m}=r / R, r$, and $R$ are the inner and outer radius, respectively. $E_{x x}, G_{x y}$, and $v_{x y}$ are elastic modulus, shear modulus, and Poisson's ratio.

And

$$
[\bar{Q}]=[T]^{-1}[Q][T]^{-T},
$$

in which 


$$
\begin{gathered}
{[T]=\left[\begin{array}{ccccc}
m^{2} & n^{2} & 0 & 0 & 2 m n \\
n^{2} & m^{2} & 0 & 0 & -2 m n \\
0 & 0 & m & -n & 0 \\
0 & 0 & n & m & 0 \\
-m n & m n & 0 & 0 & m^{2}-n^{2}
\end{array}\right],} \\
{[Q]=\left[\begin{array}{ccccc}
Q_{11} & Q_{12} & 0 & 0 & Q_{16} \\
Q_{21} & Q_{22} & 0 & 0 & Q_{26} \\
0 & 0 & Q_{44} & 0 & 0 \\
0 & 0 & 0 & Q_{55} & 0 \\
0 & 0 & 0 & 0 & Q_{66}
\end{array}\right],}
\end{gathered}
$$

where $[T]$ is transformation matrix and $[Q]$ is the stiffness matrix, $m=\cos \alpha, n=\sin \alpha, \alpha$ is the angle made by fiber direction with respect to the $x$-axis of the coordinate system $(x, s, \xi)$. The stiffness arrays $Q_{i j}$ are determined according to the material properties of the lamina:

$$
\begin{aligned}
Q_{11} & =\frac{E_{11}}{1-v_{12} v_{21}}, \\
Q_{12} & =Q_{21}=\frac{v_{12} E_{22}}{1-v_{12} v_{21}}, \\
Q_{22} & =\frac{E_{22}}{1-v_{12} v_{21}}, \\
Q_{44} & =\kappa G_{23}, \\
Q_{55} & =\kappa G_{13}, \\
Q_{66} & =G_{12} .
\end{aligned}
$$

In addition, the mass terms $m_{c}, I_{y}$, and $I_{z}$ in (14) are expressed as

$$
m_{c}=\iint_{A} \rho \mathrm{d} A, I_{y}=\iint_{A} \rho z^{2} \mathrm{~d} A, I_{z}=\iint_{A} \rho y^{2} \mathrm{~d} A .
$$

By considering the mixture rule of composition, the modulus and Poisson's ratio of the shaft embedded with SMA wires can be deduced [22]:

$$
\begin{aligned}
& E_{11}=E_{s} V_{s}+E_{11 c}\left(1-V_{s}\right), \\
& E_{22}=\frac{E_{22 c} E_{s}}{E_{22 c} V_{s}+E_{s}\left(1-V_{s}\right)}, \\
& G_{12}=\frac{G_{12 c} G_{s}}{G_{12 c} V_{s}+G_{s}\left(1-V_{s}\right)}, \\
& v_{12}=v_{12 s}+V_{s} \nu_{12 c}\left(1-V_{s}\right), \\
& G_{s}=\frac{E_{s}}{2\left(1+v_{12 s}\right)},
\end{aligned}
$$

where the subscripts $s$ and $c$ denote SMA wires and composite matrix, respectively, and $V_{s}$ represents volume fraction of SMA wires.
The axial tensions $N^{S M A}$ and $N^{\Delta T}$ in (14) are given by

$$
\begin{aligned}
N^{\mathrm{SMA}}= & \frac{\pi d^{2}}{4} n \sigma_{r} \cos \left[\arctan \left(\frac{1-\sigma}{L} r_{R}\right)\right], \\
N^{\Delta T}= & 2 \pi r \sum_{k=1}^{n}\left[\left(\bar{Q}_{11 k} \bar{\alpha}_{x k}+\bar{Q}_{12 k} \bar{\alpha}_{y k}+\bar{Q}_{16 k} \bar{\alpha}_{x y k}\right)\right. \\
& \left.\times\left(z_{k}-z_{k-1}\right) \Delta T \cos \left[\arctan \left(\frac{1-\sigma}{L} r_{R}\right)\right]\right],
\end{aligned}
$$

where $d, n$ represent the diameter and number of the SMA wires; $\bar{\alpha}_{x k}, \bar{\alpha}_{y k}, \bar{\alpha}_{x y k}$ denote the reduced thermal expansion coefficients in the $k$ th layer of composite medium; and $\sigma_{r}$ represents the recovery stress of the constrained SMA wires. Based on the one-dimensional model of SMA proposed by Brinson [23] and assuming all SMA wires are fully constrained, the expressions for the recovery stress of SMA wires during heating and cooling can be obtained in [17]. The expressions are not given in this paper for the sake of simplicity.

The governing equation (14) can be used for a tapered composite thin-walled rotating shaft embedded with SMA wires with arbitrary boundary conditions. The following three cases of boundary conditions are considered in this paper.

(i) Clamped-clamped (C-C):

$$
\begin{gathered}
V(0)=0, \\
W(0)=0, \\
\Psi_{y}(0)=0, \\
\Psi_{z}(0)=0, \\
V(L)=0, \\
W(L)=0, \\
\Psi_{y}(L)=0, \\
\Psi_{z}(L)=0 .
\end{gathered}
$$

(ii) Simply supported-simply supported (S-S):

$$
\begin{aligned}
V(0) & =0, \\
W(0) & =0, \\
M_{y}(0) & =0, \\
M_{z}(0) & =0, \\
V(L) & =0, \\
W(L) & =0, \\
M_{y}(L) & =0, \\
M_{z}(L) & =0 .
\end{aligned}
$$

(iii) Clamped-free (C-F): 


$$
\begin{gathered}
V(0)=0, \\
W(0)=0, \\
\Psi_{y}(0)=0, \\
\Psi_{z}(0)=0, \\
Q_{y}(L)=0, \\
Q_{z}(L)=0, \\
M_{y}(L)=0, \\
M_{z}(L)=0 .
\end{gathered}
$$

3.3. Approximate Solution Method. The GDQM is a global numerical approximate technique. The derivative of a sufficiently smooth function $f(x, t)$ at the $j$ th discrete point can be approximated by weighted sums of the function values at all the discrete points. By applying the GDQM, the $p$ th-order derivative of $f(x, t)$ is given by [24]

$$
\left.\frac{\partial^{p} f(x, t)}{\partial x^{p}}\right|_{x=x_{j}}=\sum_{k=1}^{N_{G P}} C_{j k}^{p} f\left(x_{k}, t\right), \quad j=1,2, \ldots, N_{G P},
$$

where $N_{G P}$ is the number of total discrete grid points in the $x$ direction and $C_{j k}^{p}$ is the corresponding weighting coefficient associated with the $p$ th-order derivative.

For numerical computation, the grid points with the following coordinates [24] are used:

$$
x_{j}=\frac{L}{2}\left(1-\cos \left(\frac{j-1}{N_{G P}-1} \pi\right)\right), \quad j=1,2, \ldots, N_{G P} .
$$

To find the approximate solution of the composite rotating shaft, the bending deformation and bending angle are assumed as follows:

$$
\begin{aligned}
& v_{0}(x, t)=V(x) e^{i \omega t}, \\
& w_{0}(x, t)=W(x) e^{i \omega t}, \\
& \varphi_{y}(x, t)=\Psi_{y}(x) e^{i \omega t}, \\
& \varphi_{z}(x, t)=\Psi_{z}(x) e^{i \omega t},
\end{aligned}
$$

where $V(x), W(x), \Psi_{y}(x)$, and $\Psi_{z}(x)$ are the indefinite functions of the $x$-direction and $\omega$ is the natural frequency, $i=\sqrt{-1}$.

Substituting the displacement components (31) into the governing equation (14), a set of ordinary differential equations with variable coefficients toward the $x$-direction is derived:

$$
L^{*} U^{*}=0
$$

where $U^{* \mathrm{~T}}=\left\{V(x), W(x), \Psi_{y}(x), \Psi_{z}(x)\right\}$ is an unknown spatial function vector of mode shape and $L^{*}=\left[L_{i j}^{*}\right](i, j=$ $1, \ldots, 4)$ is a $4 \times 4$ matrix of $U^{*}$ and is defined as

$$
L^{*}=-\omega^{2} \mathbf{M}_{1}+i \omega \mathbf{G}_{1}+\mathbf{K}_{1}+\mathbf{K}_{\Omega},
$$

where

$$
\begin{aligned}
\mathbf{M}_{1} & =\left[\begin{array}{ccccc}
m_{c} & 0 & 0 & 0 & \\
0 & m_{c} & 0 & 0 & \\
0 & 0 & -I_{z} & 0 & \\
0 & 0 & 0 & -I_{y}
\end{array}\right], \\
\mathbf{G}_{1} & =\left[\begin{array}{cccc}
0 & -2 \Omega m_{c} & 0 & 0 \\
2 \Omega m_{c} & 0 & 0 & 0 \\
0 & 0 & 0 & 0 \\
0 & 0 & 0 & 0
\end{array}\right], \\
\mathbf{K}_{\Omega} & =\left[\begin{array}{cccc}
-m_{c} \Omega^{2} & 0 & 0 & 0 \\
0 & -m_{c} \Omega^{2} & 0 & 0 \\
0 & 0 & 0 & 0 \\
0 & 0 & 0 & 0
\end{array}\right],
\end{aligned}
$$




$$
\mathbf{K}_{1}=\left[\begin{array}{cccc}
\left(-C_{55}(x)+N^{S M A}-N^{\Delta T}\right) \frac{\partial^{2}}{\partial x^{2}} & 0 & C_{55}(x) \frac{\partial}{\partial x} & -C_{35}(x) \frac{\partial^{2}}{\partial x^{2}} \\
0 & \left(-C_{66}(x)+N^{S M A}-N^{\Delta T}\right) \frac{\partial^{2}}{\partial x^{2}} & -C_{46}(x) \frac{\partial^{2}}{\partial x^{2}} & C_{66}(x) \frac{\partial}{\partial x} \\
-C_{55}(x) \frac{\partial}{\partial x} & -C_{46}(x) \frac{\partial^{2}}{\partial x^{2}} & -C_{44}(x) \frac{\partial^{2}}{\partial x^{2}}+C_{55}(x) & \left(C_{46}(x)-C_{35}(x)\right) \frac{\partial}{\partial x} \\
-C_{35}(x) \frac{\partial^{2}}{\partial x^{2}} & -C_{66}(x) \frac{\partial}{\partial x} & \left(C_{35}(x)-C_{46}(x)\right) \frac{\partial}{\partial x} & -C_{33}(x) \frac{\partial^{2}}{\partial x^{2}}+C_{66}(x)
\end{array}\right] .
$$

By imposing equation (29) to equation (33) and rearranging equation (33) according to the orders of derivatives, the approximate governing equations are obtained in the form of linear discrete algebraic equations:

$$
\left.L^{* *} U^{* *}\right|_{x=x_{j}}=\left.L_{4 \times 15}^{* *} U_{15 \times 1}^{* *}\right|_{x=x_{j}}=0, \quad j=1,2, \ldots, N_{G P},
$$

where $N_{G P}$ is the total discrete grid points in the $x$-direction and $U^{* *}$ is written as

$$
\begin{aligned}
\left.U^{* * T}\right|_{x=x_{j}}=\{ & \left\{\left(x_{j}\right), V^{(1)}\left(x_{j}\right), V^{(2)}\left(x_{j}\right), W\left(x_{j}\right), V^{(1)}\left(x_{j}\right), V^{(2)}\left(x_{j}\right), \Psi_{y}\left(x_{j}\right),\right. \\
& \left.\cdot \Psi_{y}^{(1)}\left(x_{j}\right), \Psi_{y}^{(2)}\left(x_{j}\right), \Psi_{z}\left(x_{j}\right), \Psi_{z}^{(1)}\left(x_{j}\right), \Psi_{z}^{(2)}\left(x_{j}\right)\right\},
\end{aligned}
$$

in which

$$
\begin{aligned}
& V^{(p)}\left(x_{j}\right)=\sum_{k=1}^{N_{G P}} C_{j k}^{(p)} V\left(x_{k}, t\right), W^{(p)}\left(x_{j}\right)=\sum_{k=1}^{N_{G P}} C_{j k}^{(p)} W\left(x_{k}, t\right), \\
& \Psi_{y}^{(p)}\left(x_{j}\right)=\sum_{k=1}^{N_{G P}} C_{j k}^{(p)} \Psi_{y}\left(x_{k}, t\right), \Psi_{z}^{(p)}\left(x_{j}\right)=\sum_{k=1}^{N_{G P}} C_{j k}^{(p)} \Psi_{y}\left(x_{k}, t\right), \quad(p=1,2) .
\end{aligned}
$$

For the given boundary conditions, imposing equation (35) on every discrete grid point and the discretized form of the boundary conditions is achieved.

Therefore, the eigenvalue equation can be expressed in the following form:

$$
\left(\mathbf{M} \omega^{2}\right) d+(\mathbf{G i} \omega) d+\mathbf{K} d=0,
$$

where $\mathbf{M}, \mathbf{G}$, and $\mathbf{K}$ are the $4\left(N_{G P}-2\right) \times 4\left(N_{G P}-2\right)$ numerical coefficient matrices. The dimensions of vector $d$ are $4\left(N_{G P}-2\right)$ which can be expressed as

$$
\begin{aligned}
d^{\mathrm{T}}= & \left\{V\left(x_{2}\right), \ldots, V\left(x_{N_{G P}-1}\right), W\left(x_{2}\right), \ldots, W\left(x_{N_{G P}-1}\right),\right. \\
& \left.\left.\cdot \Psi_{y}\left(x_{2}\right), \ldots, \Psi_{y}\left(x_{N_{G P}-1}\right), \Psi_{z}\left(x_{2}\right), \ldots, \Psi_{z}\left(x_{N_{G P}-1}\right)\right\}\right\} .
\end{aligned}
$$

For a certain frequency, equation (38) can be equivalently converted into a standard form as [25]:

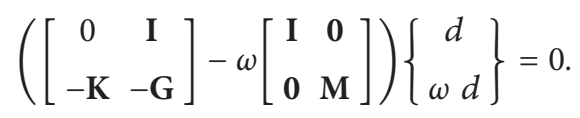

where $\mathbf{I}$ is the $4\left(N_{G P}-2\right) \times 4\left(N_{G P}-2\right)$ identity matrix. By solving (40), the vibration characteristics of the tapered composite shaft can be obtained.

\section{Numerical Simulations}

4.1. Model Verifications. The variation of natural frequencies versus rotating speed for simply supported cylindrical shaft with SMA is shown in Figure 2 from the present model with the ones from [17]. The numerical results are obtained in terms of the normalized natural frequencies and rotating rate which are defined by $\omega^{*}=\omega / \omega_{0}, \Omega^{*}=\Omega / \omega_{0}$, where $\omega_{0}=138.85 \mathrm{rad} / \mathrm{s}$ corresponds to the fundamental frequency of the nonrotating shaft with $\theta=0^{\circ}$.

It can be seen from Figure 2 that when the rotating speed is more than zero, a bifurcation of natural frequencies occurs because of the gyroscopic effect. Hence, the natural frequency curve splits into an upper one and a lower one. With the increase of the rotational speed, the upper curve goes up corresponding to the forward feed $(F)$ while the lower curve goes down corresponding to the backward feed $(B)$. The 


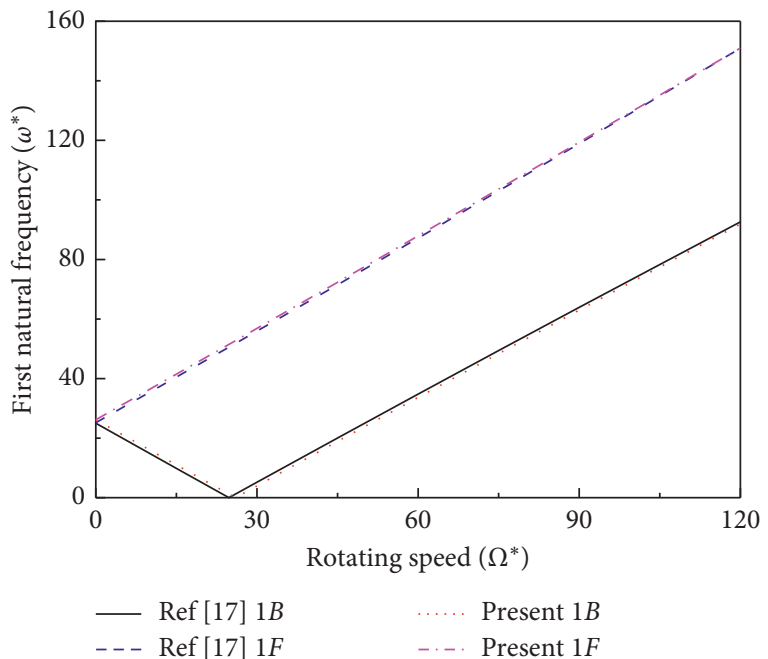

FIGURE 2: The natural frequency of a cylindrical composite thin-walled shaft with SMA versus rotating speed $\left(\theta=30^{\circ}, T=50^{\circ} \mathrm{C}, V s=0.36\right.$, $\left.\varepsilon_{0}=0.067\right)$.

TABLE 1: Mechanical properties of composite material [1].

\begin{tabular}{lcccccc}
\hline$\rho\left(\mathrm{kg} / \mathrm{m}^{3}\right)$ & $E_{11}(\mathrm{GPa})$ & $E_{22}(\mathrm{GPa})$ & $\mathrm{G}_{12}(\mathrm{GPa})$ & $\mathrm{G}_{13}(\mathrm{GPa})$ & $\mathrm{G}_{23}(\mathrm{GPa})$ & $v_{12}$ \\
\hline 1610 & 192 & 7.24 & 4.07 & 4.07 & 3.0 & 0.24 \\
\hline
\end{tabular}

TABle 2: Material properties of SMA [23].

\begin{tabular}{|c|c|c|c|c|c|c|c|c|c|c|c|c|}
\hline $\begin{array}{l}E_{A} \\
(\mathrm{MPa})\end{array}$ & $\begin{array}{c}E_{M} \\
(\mathrm{MPa})\end{array}$ & $\begin{array}{c}\sigma_{s}^{c r} \\
(\mathrm{MPa})\end{array}$ & $\begin{array}{c}\sigma_{f}^{c r} \\
(\mathrm{MPa})\end{array}$ & $\varepsilon_{L}$ & $\begin{array}{c}\Theta \\
\left(\mathrm{MPa} /{ }^{\circ} \mathrm{C}\right)\end{array}$ & $\begin{array}{l}M_{f} \\
\left({ }^{\circ} \mathrm{C}\right)\end{array}$ & $\begin{array}{l}M_{s} \\
\left({ }^{\circ} \mathrm{C}\right)\end{array}$ & $\begin{array}{c}A_{s} \\
\left({ }^{\circ} \mathrm{C}\right)\end{array}$ & $\begin{array}{l}A_{f} \\
\left({ }^{\circ} \mathrm{C}\right)\end{array}$ & $\begin{array}{c}C_{M} \\
\left(\mathrm{MPa} /{ }^{\circ} \mathrm{C}\right)\end{array}$ & $\begin{array}{c}C_{A} \\
\left(\mathrm{MPa} /{ }^{\circ} \mathrm{C}\right)\end{array}$ & $\begin{array}{c}\rho \\
\left(\mathrm{kg} / \mathrm{m}^{3}\right)\end{array}$ \\
\hline $67 \times 10^{3}$ & $26.3 \times 10^{3}$ & 100 & 170 & 0.067 & 0.55 & 9 & 18.4 & 34.5 & 49 & 8 & 13.8 & 6450 \\
\hline
\end{tabular}

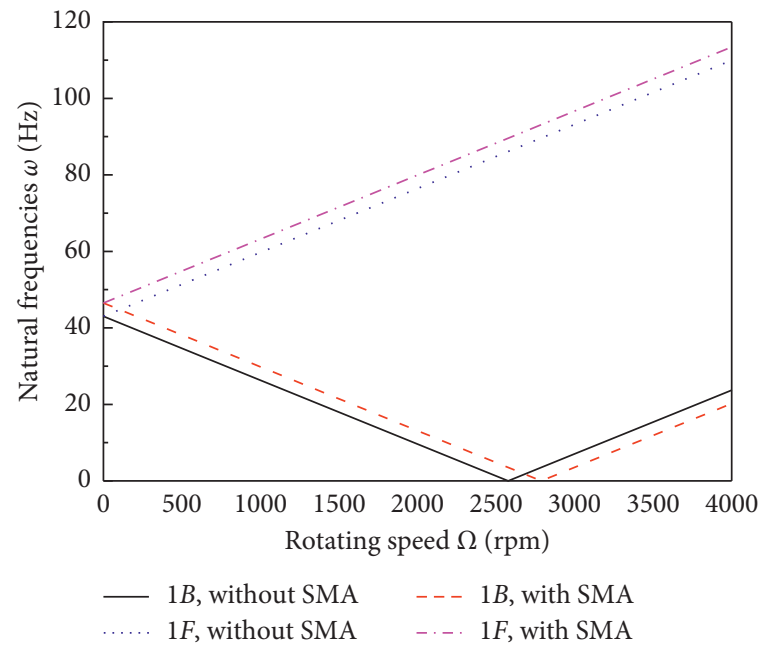

(a)

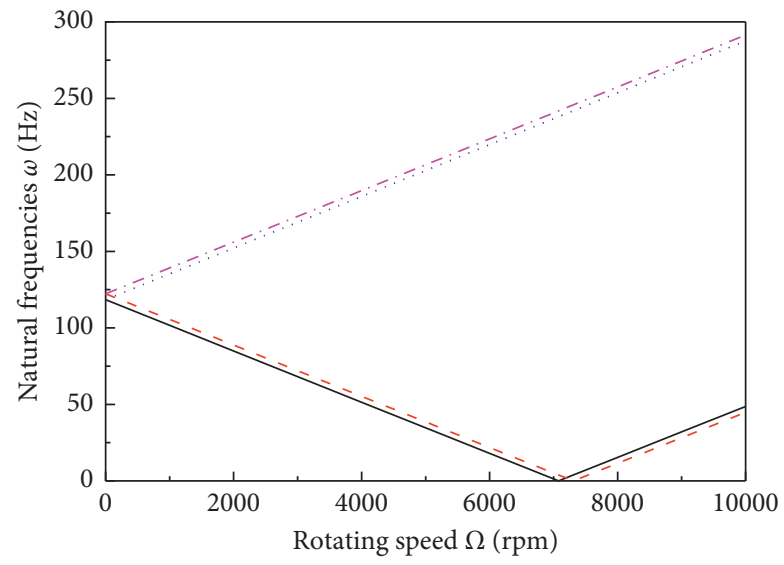

$\begin{array}{lll}- & 2 B \text {, without SMA } \\ \ldots & 2 F \text {, without SMA }\end{array}-.-2 B$, with SMA

(b)

FIGURE 3: Continued. 


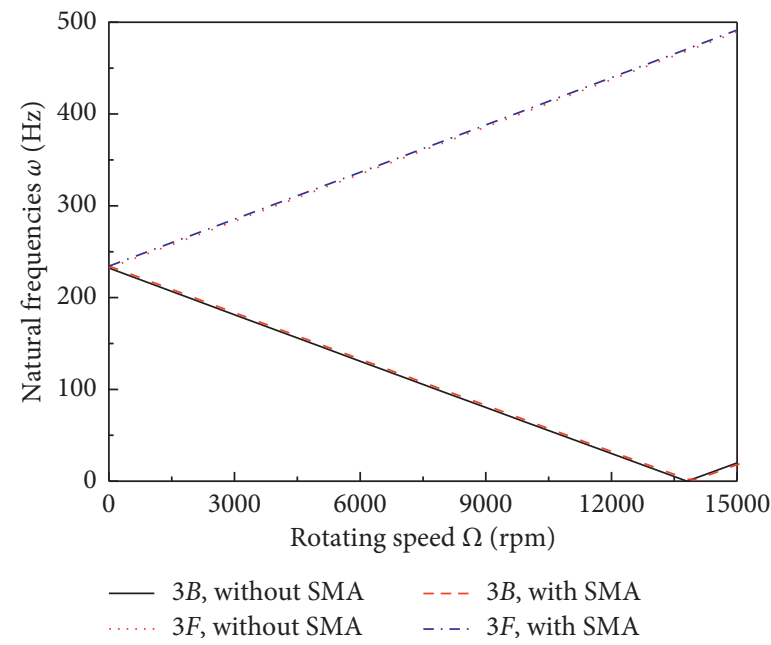

(c)

FIgURE 3: The natural frequencies versus rotating speed of the tapered composite rotating shaft with SMA and without SMA for C-C boundary condition $\left(\sigma=0.5, \theta=30^{\circ}, V s=0.1, T=50^{\circ} \mathrm{C}, \varepsilon_{0}=0.005\right)$ : (a) the first mode; (b) the second mode; (c) the third mode.

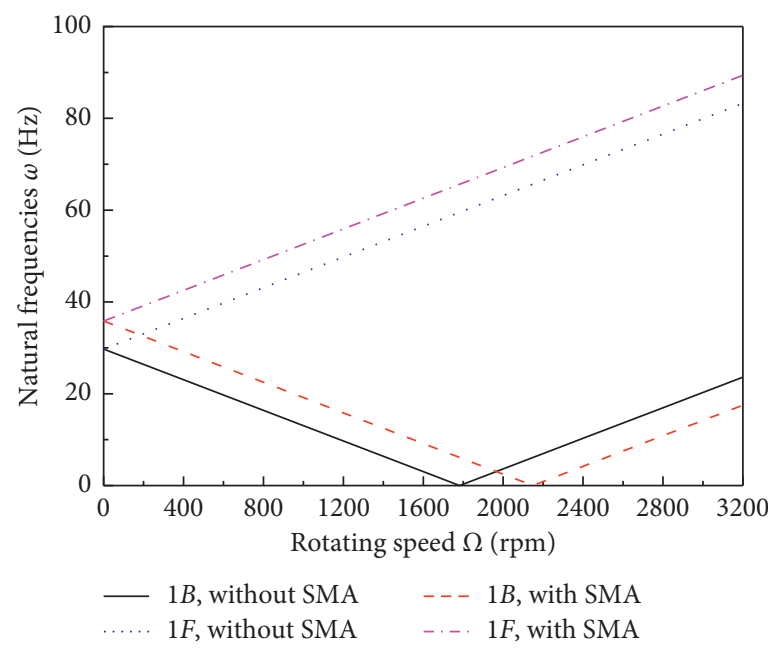

(a)

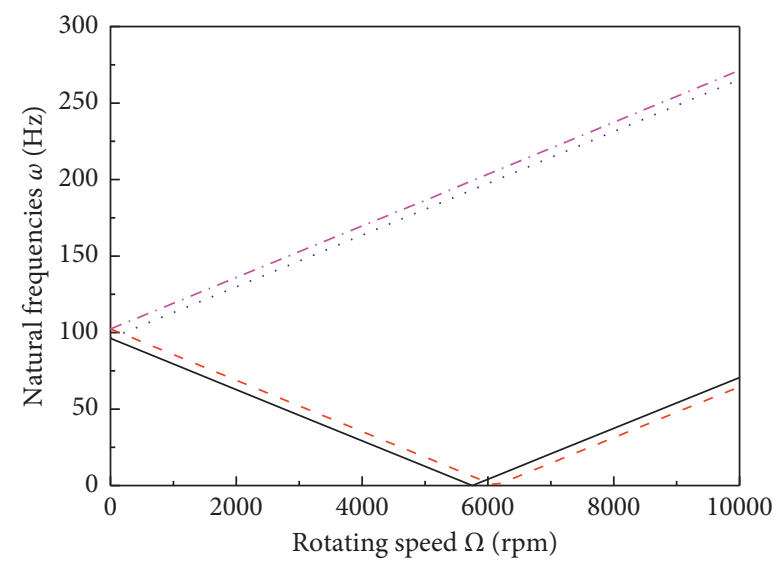

- 2B, without SMA - - - 2B, with SMA

$2 F$, without SMA $\quad-\cdot 2 F$, with SMA

(b)

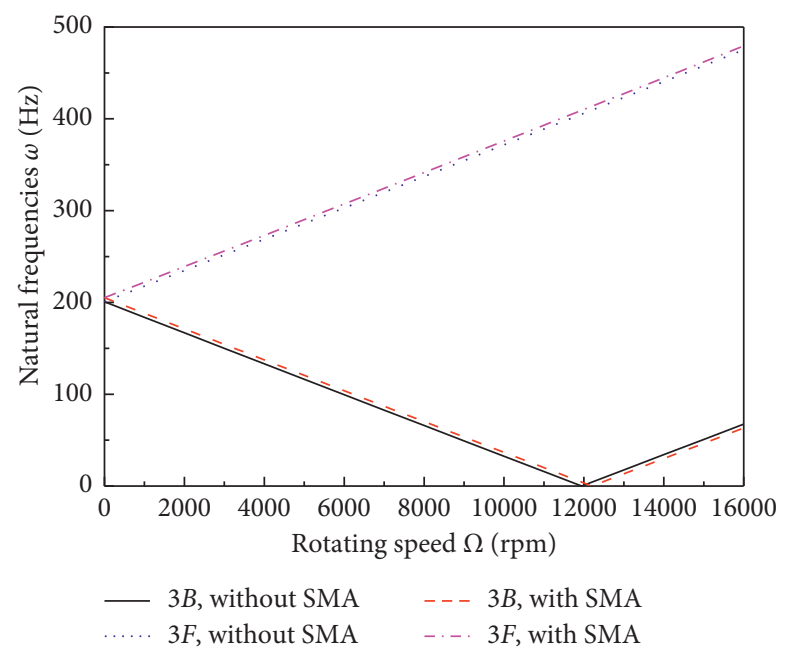

(c)

FIGURE 4: The natural frequencies versus rotating speed of the tapered composite rotating shaft with SMA and without SMA for S-S boundary condition $\left(\sigma=0.5, \theta=30^{\circ}, V s=0.1, T=50^{\circ} \mathrm{C}, \varepsilon_{0}=0.005\right)$ : (a) the first mode; (b) the second mode; (c) the third mode. 


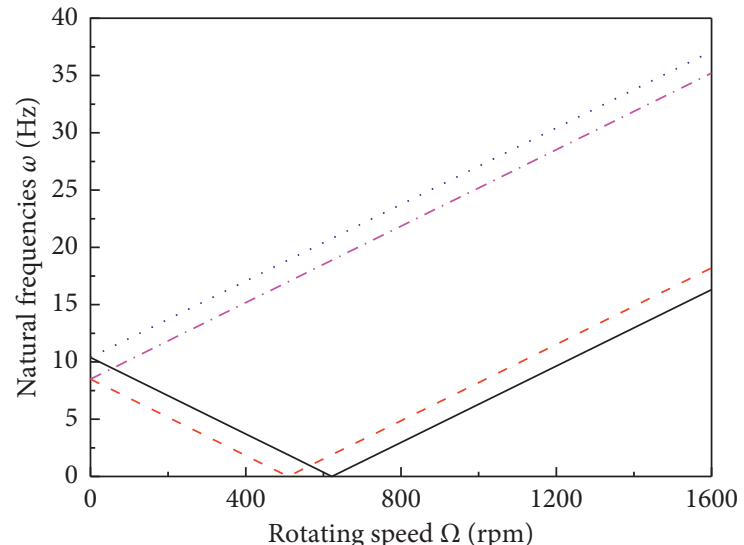

$\begin{array}{lll}1 B \text {, without SMA } & --1 B \text {, with SMA } \\ 1 & 1 F \text {, without SMA }\end{array}$

(a)

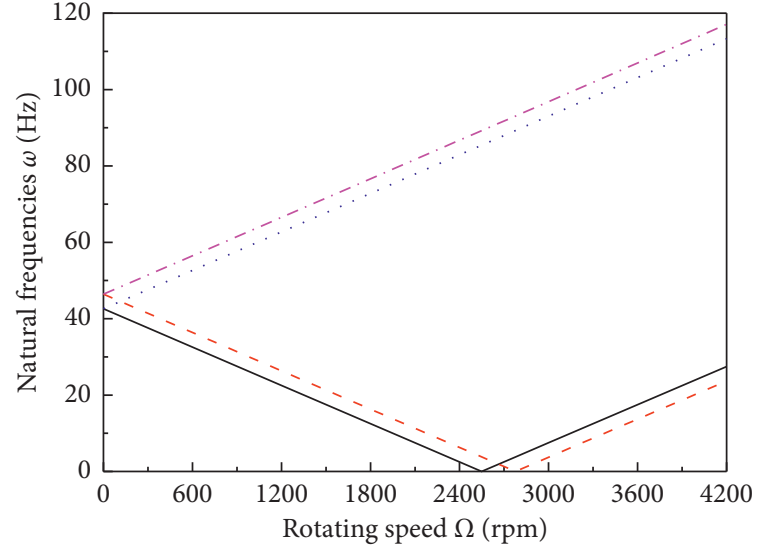

- 2B, without SMA $\quad--2 B$, with SMA

$2 F$, without SMA _... $2 F$, with SMA

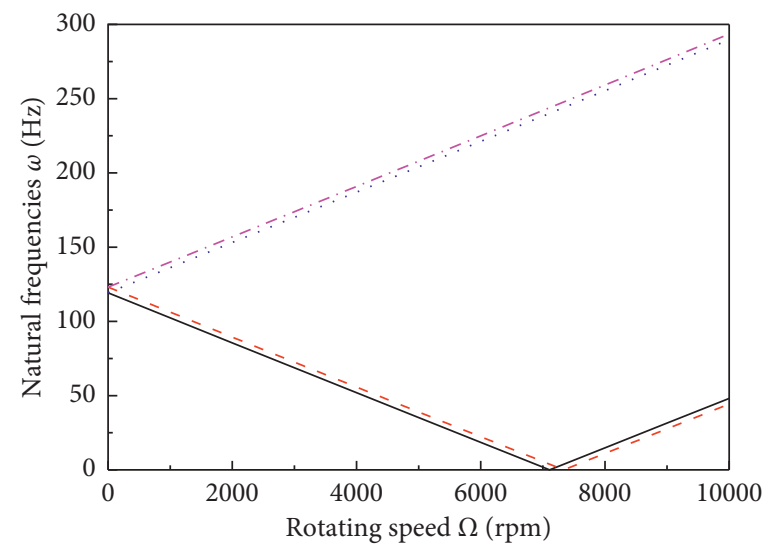

- 3B, without SMA $\quad---3 B$, with SMA

$3 F$, without SMA _... $3 F$, with SMA

(c)

Figure 5: The natural frequencies versus rotating speed of the tapered composite rotating shaft with SMA and without SMA for C-F boundary condition $\left(\sigma=0.5, \theta=30^{\circ}, V s=0.1, T=50^{\circ} \mathrm{C}, \varepsilon_{0}=0.005\right)$ : (a) the first mode; (b) the second mode; (c) the third mode.
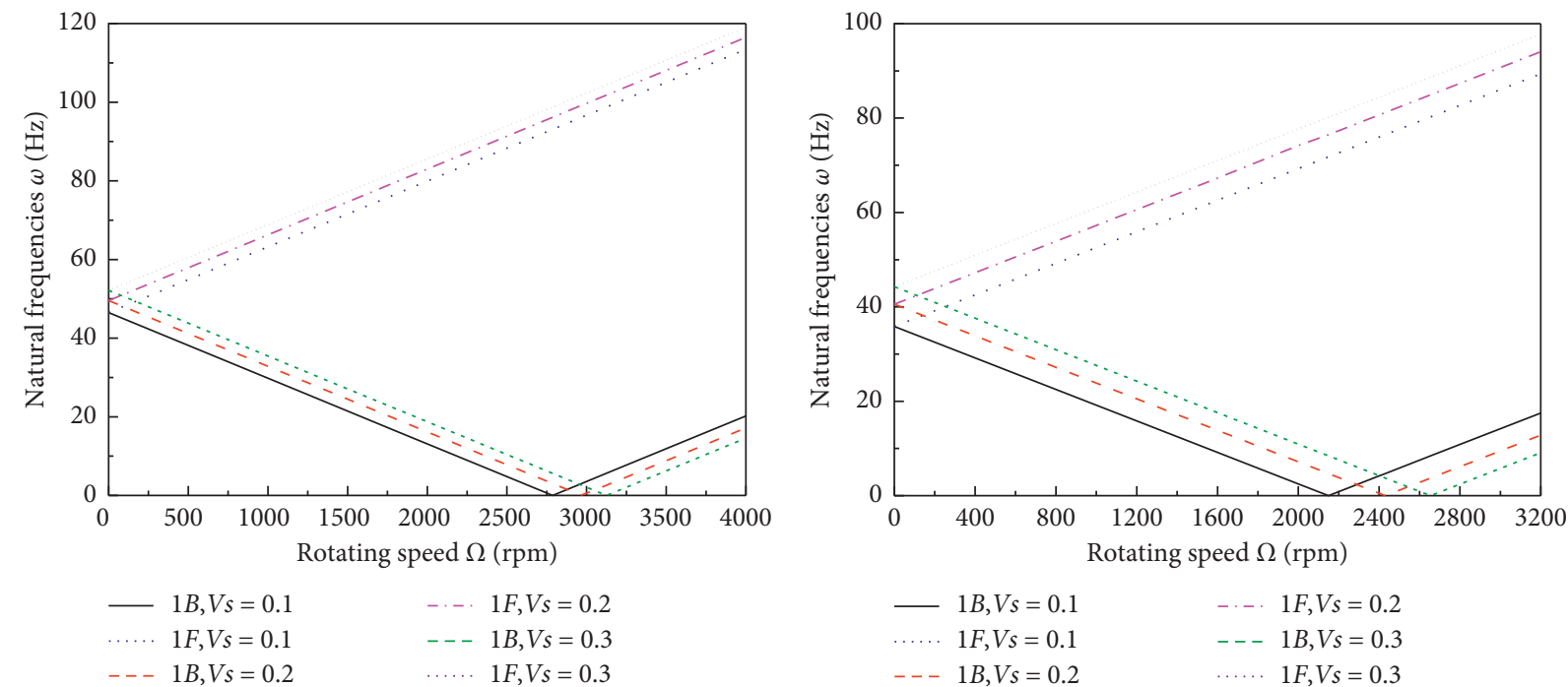

(a)

(b)

Figure 6: Continued. 


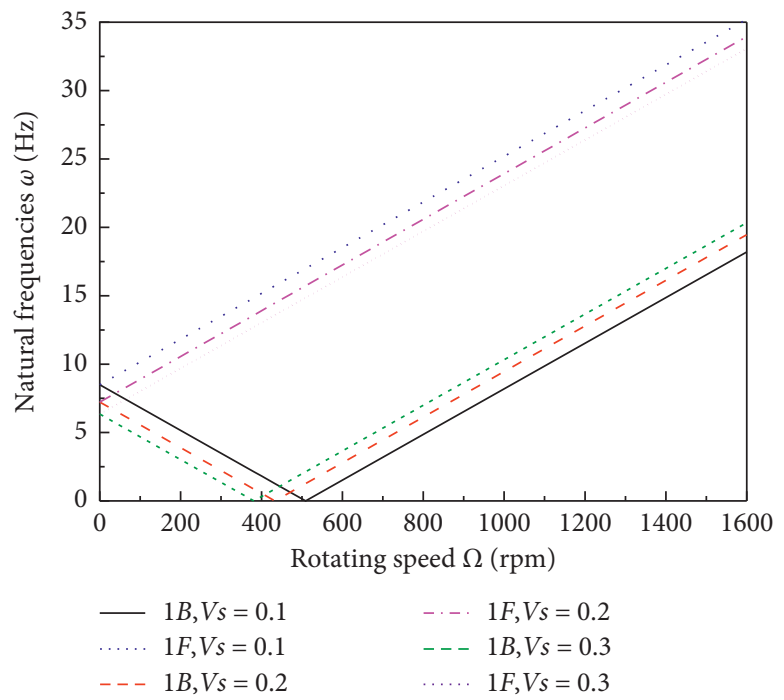

(c)

FIGURE 6: The first natural frequencies versus rotating speed of the tapered composite rotating shaft for different SMA fiber fractions $\left(\sigma=0.5, \theta=30^{\circ}, T=50^{\circ} \mathrm{C}, \varepsilon_{0}=0.005\right)$, (a) C-C; (b) S-S; (c) C-F.
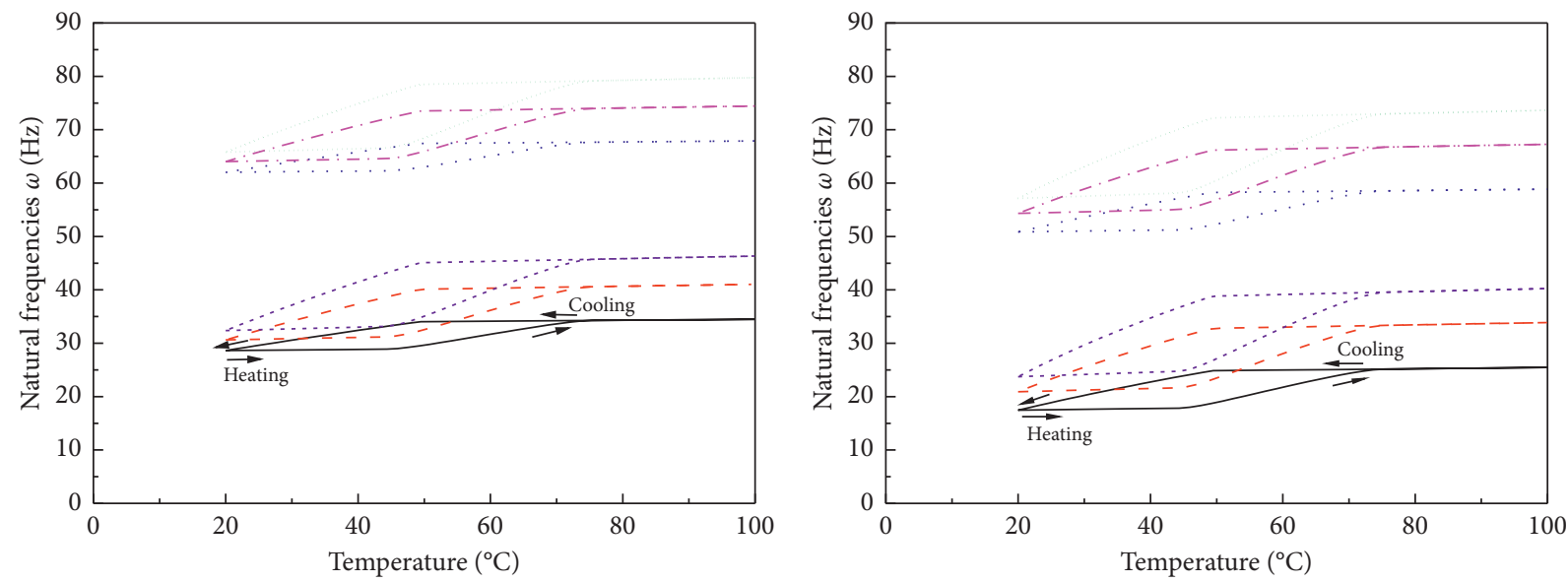
$-1 B, V s=0.1$
$1 F, V s=0.1$
$--1 B, V s=0.2$
-... $1 F, V s=0.2$
$1 B, V s=0.3$
$1 F, V s=0.3$

$\begin{aligned}-1 B, V s & =0.1 \\ --1 B, V s & =0.2\end{aligned}$

… $1 B, V s=0.3$

(a)

FIgURE 7: Continued.

(b) 


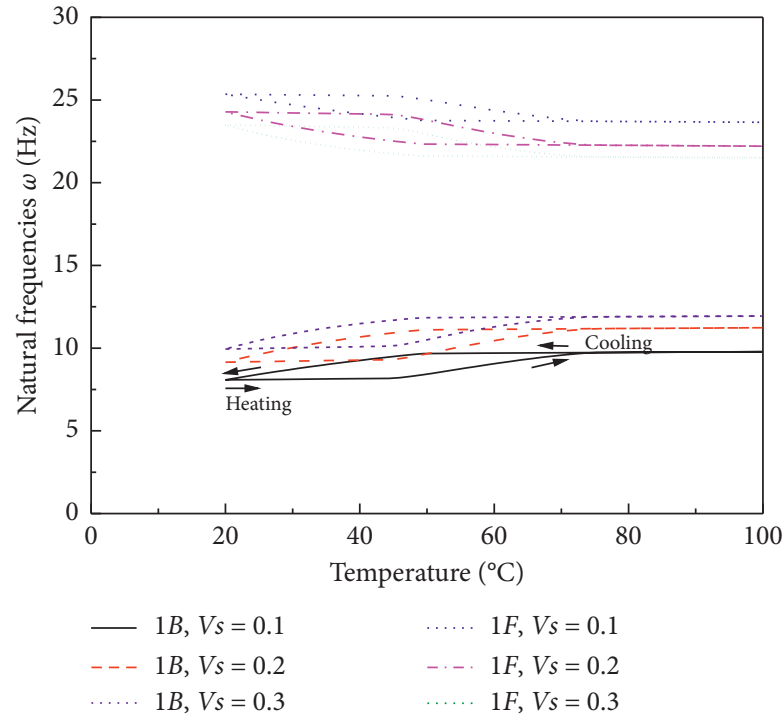

(c)

Figure 7: The first natural frequencies versus temperature of the tapered composite rotating shaft for different SMA fiber fractions $\left(\sigma=0.5, \Omega=1000 \mathrm{rpm}, \theta=30^{\circ}, \varepsilon_{0}=0.005\right)$ : (a) C-C; (b) S-S; (c) C-F.

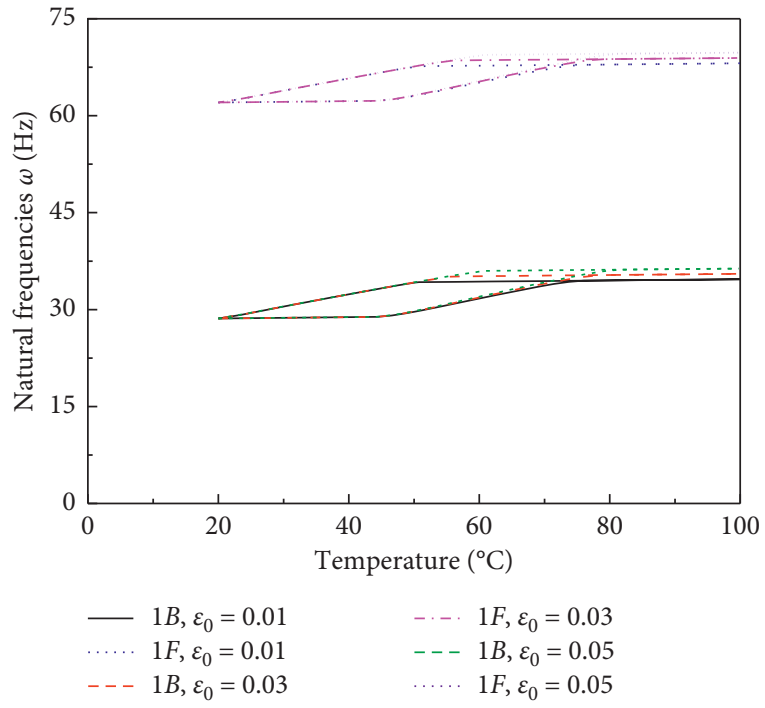

(a)

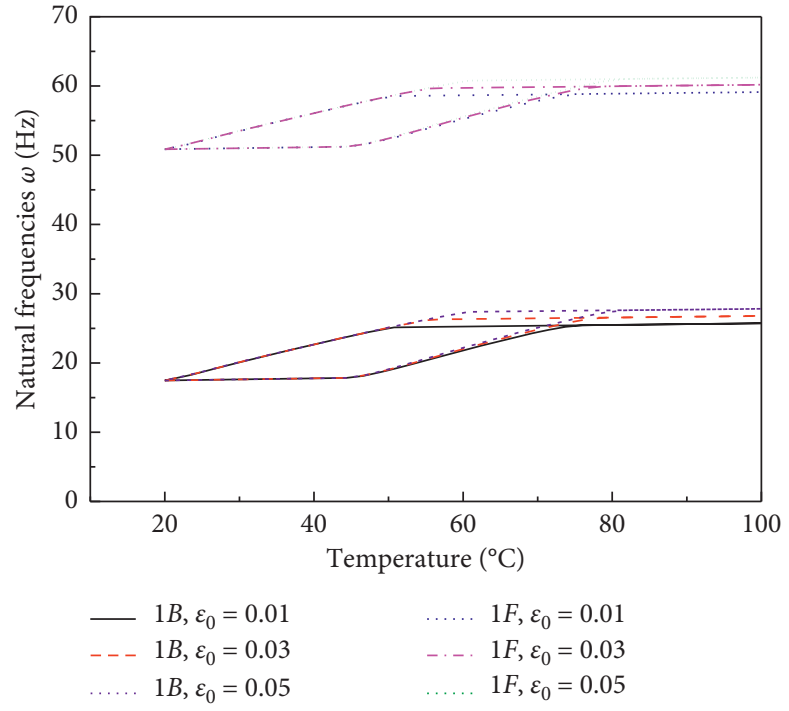

(b)

FIgURE 8: Continued. 


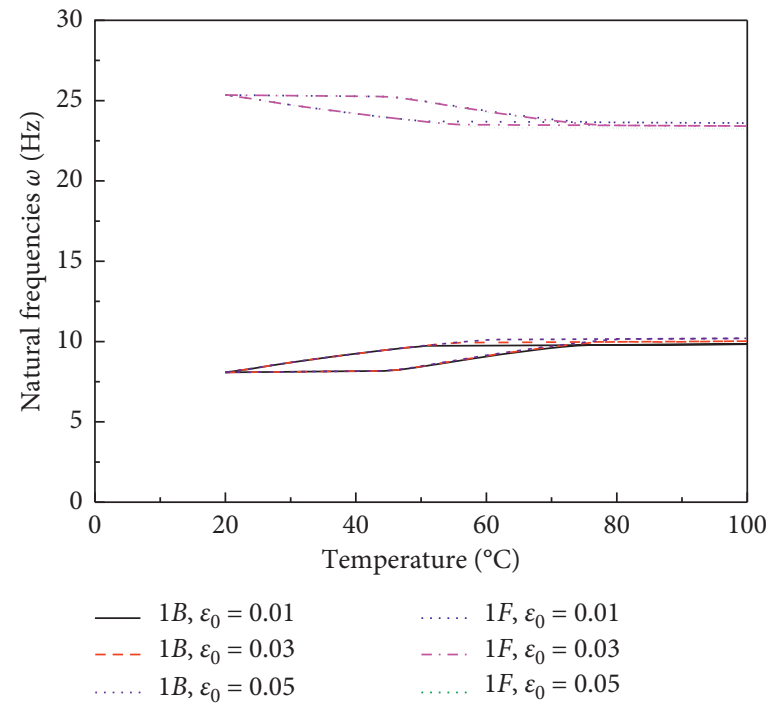

(c)

Figure 8: The first natural frequencies versus temperature of the tapered composite rotating shaft for different SMA fiber initial strain $\left(\sigma=0.5, \Omega=1000 \mathrm{rpm}, \theta=30^{\circ}, V s=0.1\right)$ : (a) C-C; (b) S-S; (c) C-F.

minimum rotating speed at which the lower curve becomes zero is referred to as the critical speed $\left(\Omega_{c r}\right)$ that corresponds to the dynamical instability of the composite rotating shaft. It also clearly appears that the present numerical results are in good agreement with those presented in [17].

4.2. Results and Discussion. In the following application, the natural frequencies and critical rotating speeds of a tapered composite shaft embedded with SMA wires are computed using the present model. The numerical calculations are performed by considering the shaft made of graphite-epoxy whose elastic characteristics are listed in Table 1. The shaft has geometrical characteristics as $r_{R}=0.0635 \mathrm{~m}, L=2.47 \mathrm{~m}$, and $h=1.321 \mathrm{~mm}$. The stacking sequence of the composite shaft is $[ \pm \theta]_{5}$. The material properties of SMA wires used in the numerical simulations are listed in Table 2. This paper is mainly focused on the effect of activating SMA wires, so the taper ratio $\sigma$ of the tapered composite rotating shaft is assumed unchanged firstly.

Figures 3-5 show the first three natural frequencies versus rotating speed of the tapered composite rotating shaft with SMA activation and without SMA activation for different boundary conditions $\left(\sigma=0.5, \theta=30^{\circ}, V s=0.1, T=50^{\circ} \mathrm{C}, \varepsilon_{0}=0.005\right)$. Figures 3 and 4 clearly indicate that the natural frequency and critical speed of the composite rotating shaft can be increased by activating SMA wires for C-C and S-S boundary condition while it can be seen from Figure 5 that the first natural frequency of the shaft is decreased and the second and third natural frequencies are increased by activating SMA wires for $\mathrm{C}-\mathrm{F}$ boundary condition.

Figure 6 shows the variations of the first natural frequencies versus rotating speed of the tapered shaft with various boundary conditions for different fractions of SMA wires $\left(\sigma=0.5, \theta=30^{\circ}, V s=0.1, T=50^{\circ} \mathrm{C}, \varepsilon_{0}=0.005\right)$. It is obviously seen from Figures 6(a) and 6(b) that the first natural frequencies and the critical speed of the tapered composite rotating shaft increase with increasing SMA wire fraction for C-C and S-S boundary condition while the first natural frequencies and critical speeds of the composite rotating shaft decrease with increasing SMA wire fraction for C-F boundary condition which can be seen from Figure 6(c).

Figure 7 shows the variation of the first natural frequencies as function of the temperature for different SMA wire fractions $\left(\sigma=0.5, \Omega=1000 \mathrm{rpm}, \theta=30^{\circ}, \varepsilon_{0}=0.005\right)$. The temperature is raised from $0^{\circ} \mathrm{C}$ to $100^{\circ} \mathrm{C}$ and then dropped to $0^{\circ} \mathrm{C}$. Accordingly, the phase transformation from the martensite to the austenite $(M \longrightarrow A)$ is induced in the SMA wires during the heating stage, and the phase transformation from the austenite to the martensite $(A \longrightarrow M)$ is induced during the cooling stage. It can be seen from Figure 6 that the curves of natural frequencies changing with temperature are hysteretic loops. Figures $7(\mathrm{a})$ and $7(\mathrm{~b})$ represent the composite shaft with C-C and S-S boundary condition, respectively. As shown in the figures, The natural frequencies increase with the increase in temperature during the heating stage and decline with the decrease in temperature during the cooling stage. The increase of the SMA wire fraction is accompanied by the shift of these hysteresis loops towards higher natural frequencies. Figure 7(c) represents the composite shaft with $\mathrm{C}-\mathrm{F}$ boundary condition. The figure indicates that the forward natural frequencies decrease with the increase in temperature during the heating stage and increase with the decrease in temperature during the cooling stage. Furthermore, the increase of the SMA wire fraction is accompanied by the shift of hysteresis loop towards lower natural frequencies. The variation trend of the backward natural frequencies curves is similar to Figures $7(\mathrm{a})$ and $7(\mathrm{~b})$.

Figure 8 shows the variation of the first natural frequencies versus temperature of the tapered composite 


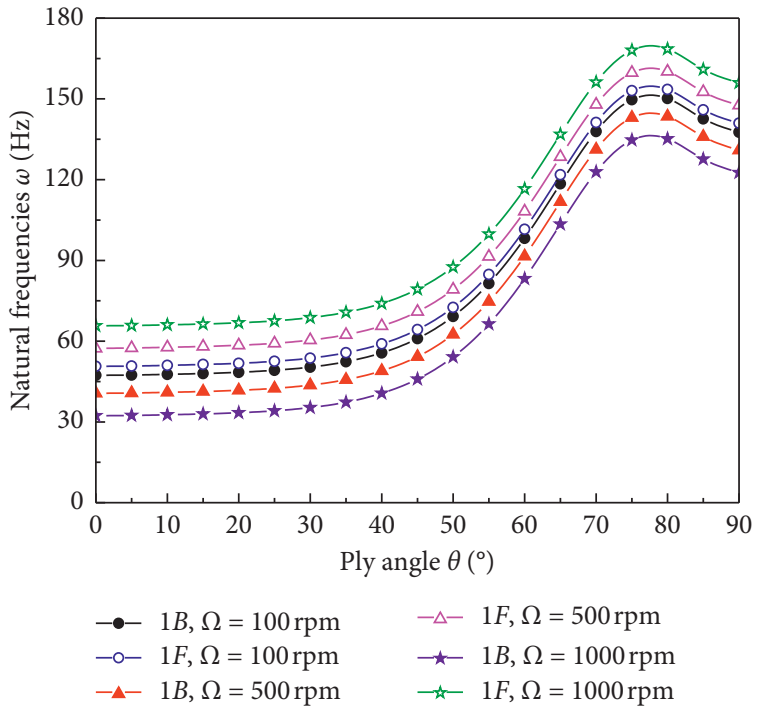

(a)

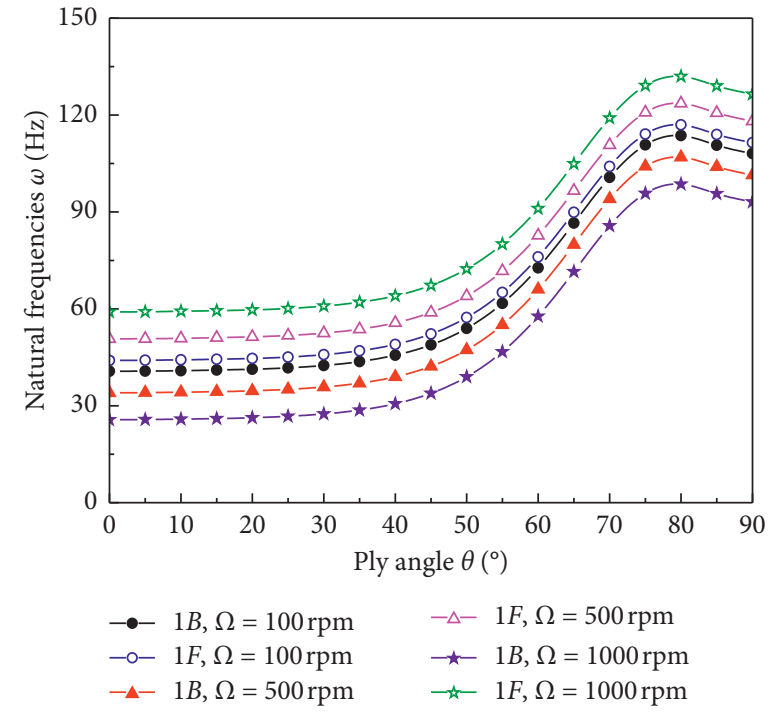

(b)

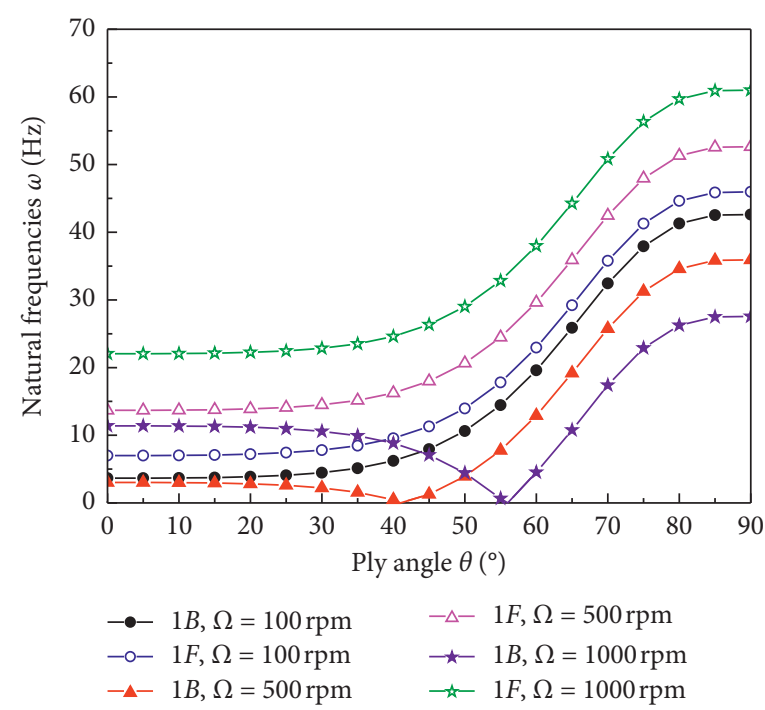

(c)

Figure 9: The first natural frequencies versus ply angle of the tapered composite rotating shaft for different rotating speeds $\left(\sigma=0.5, V s=0.3, T=50^{\circ} \mathrm{C}, \varepsilon_{0}=0.05\right)$ : (a) C-C; (b) S-S; (c) C-F.

rotating shaft for different SMA wire initial strain. It can be seen from the figure that the initial strain of SMA wire has little effect on the natural frequency of the rotating shaft during the heating process. During the cooling process, the natural frequency of the rotating shaft increases with the increase of the initial strain of SMA wire for the composite shaft with C-C and S-S boundary conditions. The forward natural frequency decreases with the increase of the initial strain of SMA wire while the backward natural frequency increases with the increase of the initial strain of SMA wire for the shaft with C-F boundary condition.

Figure 9 shows the variation of the first natural frequencies versus ply angle of the tapered shaft for different rotating speeds. The first forward frequencies increase with the increase of the rotating speeds while the first backward frequencies decrease with the increase of the rotating speeds for the composite shaft with $\mathrm{C}-\mathrm{C}$ and S-S boundary conditions. The first forward frequencies increase with the increase of the rotating speeds, and the first backward frequencies decrease with the increase of the rotating speeds $\left(\Omega>\Omega_{c r}\right)$ or increase with the increase of the rotating speeds $\left(\Omega<\Omega_{c r}\right)$ for the composite shaft with $\mathrm{C}-\mathrm{F}$ boundary condition.

Tables 3-5 represent the effect of SMA wires fractions and taper ratio on the critical rotating speed of the tapered composite rotating shaft with $\mathrm{C}-\mathrm{C}, \mathrm{S}-\mathrm{S}$, and $\mathrm{C}-\mathrm{F}$ boundary condition in the heating process at temperature $T=50^{\circ} \mathrm{C}$, respectively. The results show that the critical rotating speed increases with the increase of SMA wires fraction and taper ratio of the shaft with $\mathrm{C}-\mathrm{C}$ and S-S boundary conditions, while the critical speed decreases with the increase of SMA wires fraction and the taper ratio of the shaft with C-F boundary condition. 
TABLE 3: The critical rotating speed corresponding to the different SMA wires fractions and taper ratio for $\mathrm{C}-\mathrm{C}$ boundary condition $\left(M \longrightarrow A, T=50^{\circ} \mathrm{C}, \varepsilon_{0}=0.05, \theta=30^{\circ}\right)$.

\begin{tabular}{lccccc}
\hline \multirow{2}{*}{$V_{s}$} & $\sigma=0.2$ & $\sigma=0.4$ & $\sigma=0.6$ & $\sigma=0.8$ & $\sigma=1$ \\
\hline 0 & 288.7726 & 373.2199 & 446.1622 & 513.1162 & 576.2055 \\
0.1 & 336.2508 & 409.5044 & 476.5109 & 539.6059 & 601.8750 \\
0.2 & 375.2434 & 440.5979 & 503.3052 & 565.2639 & 626.6544 \\
0.3 & 407.0560 & 466.9272 & 526.4565 & 587.5596 & 648.3361 \\
0.4 & 433.6116 & 489.6077 & 546.7068 & 605.8255 & 667.4872 \\
0.5 & 456.2062 & 509.3690 & 564.5955 & 623.3322 & 684.5385 \\
\hline
\end{tabular}

TABLE 4: The critical rotating speed corresponding to the different SMA wire fractions and taper ratio for S-S boundary condition $\left(M \longrightarrow A, T=50^{\circ} \mathrm{C}, \varepsilon_{0}=0.05, \theta=30^{\circ}\right)$.

\begin{tabular}{lccccc}
\hline \multirow{2}{*}{$V_{s}$} & $\sigma=0.2$ & $\sigma=0.4$ & $\sigma=0.6$ & $\sigma=0.8$ & $\sigma=1$ \\
\hline 0 & 201.4930 & 258.3495 & 308.2733 & 354.4699 & 398.2391 \\
0.1 & 290.7035 & 323.4748 & 360.5079 & 398.6258 & 439.7155 \\
0.2 & 344.3648 & 370.9844 & 402.2928 & 438.4120 & 477.5412 \\
0.3 & 383.2343 & 403.6488 & 436.0954 & 471.4010 & 509.4798 \\
0.4 & 413.8560 & 437.6519 & 464.4654 & 497.5642 & 536.9760 \\
0.5 & 439.0786 & 462.7169 & 488.7473 & 522.0381 & 560.9935 \\
\hline
\end{tabular}

TABLE 5: The critical rotating speed corresponding to the different SMA wires fractions and taper ratio for C-F boundary condition $\left(M \longrightarrow A, T=50^{\circ} \mathrm{C}, \varepsilon_{0}=0.05, \theta=30^{\circ}\right)$.

\begin{tabular}{lccccc}
\hline \multirow{2}{*}{$V_{s}$} & $\sigma=0.2$ & $\sigma=0.4$ & $\sigma=0.6$ & $\sigma=0.8$ & $\sigma=1$ \\
\hline 0 & 111.6599 & 102.0724 & 96.8776 & 93.5077 & 90.9933 \\
0.1 & 90.3048 & 83.3968 & 79.5294 & 76.9749 & 73.9555 \\
0.2 & 80.5617 & 71.7104 & 67.2729 & 63.6451 & 60.0068 \\
0.3 & 75.6295 & 64.1110 & 58.4846 & 53.7358 & 49.3613 \\
0.4 & 68.5333 & 58.9458 & 51.9873 & 46.6541 & 41.0534 \\
0.5 & 64.9065 & 55.3190 & 47.0751 & 40.6724 & 34.4605 \\
\hline
\end{tabular}

\section{Conclusions}

A model was presented for the study of the dynamic behavior of the tapered composite thin-walled rotating shaft embedded with SMA wires. The developed model was used to predict the natural frequencies and dynamical stability. A refined VAM and Hamilton's principle were used to establish the vibration differential equations of the shaft, and the equations were solved by the GDQM. For this investigation, the study of the effects of SMA wires activation on the natural frequencies and critical rotating speeds of the composite shaft was done. Because of lack of publications in the case of variable cross section composite shaft embedded with SMA wires for different boundary conditions, the numerical results are helpful to improve the understanding of the dynamic characteristics of the tapered composite shaft embedded with SMA wires and to provide guidance for designing of the composite shaft with different boundary conditions.

According to the numerical results, the following can be concluded:

(1) The activation of the SMA wires led to a shift in modal frequency of the tapered composite rotating shaft obviously.

(2) The SMA wires fraction affects the actuation performance of SMA significantly. The more the SMA wires embedded in the tapered composite rotating shaft, the stronger the ability to adjust the dynamic characteristics of the shaft.

(3) The initial strain of SMA wires appears to have a marginal effect on the dynamical behaviors of the shaft.

(4) After activation of the SMA wires, the critical rotating speed of the shaft increases with the increase of taper ratio of the shaft with C-C and S-S boundary conditions, but the critical rotating speed decreases with the increase of taper ratio of the shaft with C-F boundary condition.

(5) Compared with without SMA activation, the effect of activation of SMA wires on the critical rotating speed of the tapered composite rotating shaft during the cooling process is more obvious than the heating process.

\section{Data Availability}

The data used to support the findings of this study are available from the corresponding author upon request.

\section{Conflicts of Interest}

The authors declare that there are no conflicts of interest regarding the publication of this paper.

\section{Acknowledgments}

This study was supported by the National Natural Science Foundation of China (Grant no. 11672166).

\section{References}

[1] W. Kim, A. Argento, and R. A. Scott, "Free vibration of a rotating tapered composite Timoshenko shaft," Journal of Sound and Vibration, vol. 226, no. 1, pp. 125-147, 1999.

[2] W. Kim, Vibration of a Rotating Tapered Composite Shaft and Application to High Speed Cutting, University of Michigan, Ann Arbor, MI, USA, 1999.

[3] W. Kim, A. Argento, and R. A. Scott, "Forced vibration and dynamic stability of a rotating tapered composite Timoshenko shaft: bending motions in end-milling operations," Journal of Sound and Vibration, vol. 246, no. 4, pp. 583-600, 2001.

[4] W. Kim, A. Argento, and R. A. Scott, "Rotating tapered composite shafts: forced torsional and extensional motions and static strength," Journal of Vibration and Acoustics, vol. 123, no. 1, pp. 24-29, 2001. 
[5] S. Na, H. Yoon, and L. Librescu, "Effect of taper ratio on vibration and stability of a composite thin-walled spinning shaft," Thin-Walled Structures, vol. 44, no. 3, pp. 362-371, 2006.

[6] G. Ma, M. Xu, L. Chen, and Z. An, "Transverse free vibration of axially moving stepped beam with different length and tip mass," Shock and Vibration, vol. 2015, Article ID 697493, 11 pages, 2015.

[7] Z. Rachid, R. Kaddour, and H. Achache, "Dynamic calculation of a tapered shaft rotor made of composite material," Advances in Aircraft and Spacecraft Science, vol. 5, no. 1, pp. 51-71, 2018.

[8] M. Almuslman and R. Ganesan, "Vibration of tapered composite driveshaft based on the hierarchical finite element analysis," Computer Structures, vol. 209, no. 1, pp. 905-927, 2019.

[9] W. Zhong, F. Gao, Y. Ren, X. Wu, and H. Ma, "Dynamic analysis of a tapered composite thin-walled rotating shaft using the generalized differential quadrature method," Mathematical Problems in Engineering, vol. 2020, Article ID 1695430, 14 pages, 2020.

[10] A. Baz and T. Chen, "Performance of nitinol-reinforced drive shafts," SPIE-Smart Structures and Intelligent Systems, vol. 1917, pp. 791-808, 1993.

[11] K. Gupta, "Critical speed analysis of fibre reinforced composite rotor embedded with shape memory alloy wires," International Journal of Rotating Machinery, vol. 6, no. 3, pp. 201-213, 2000.

[12] S. Sawhney and S. K. Jain, Vibration Control of Fibre-Reinforced Composite Rotor Using Shape Memory Alloy (SMA) Wires (BTech Dissertation), IIT Delhi, New Delhi, India, 2001.

[13] A. Baz and T. Chen, "Torsional stiffness of NITINOL-reinforced composite drive shafts," Composites Engineering, vol. 3, no. 12, pp. 1119-1130, 1993.

[14] A. Tylikowski, "Dynamic stability of rotating composite shells with thermoactive shape memory alloy fibers," Journal of Thermal Stresses, vol. 21, no. 3-4, pp. 327-339, 1998.

[15] A. Tylikowski and R. B. Hetnarski, "Semiactive control of a shape memory alloy hybrid composite rotating shaft," International Journal of Solids and Structures, vol. 38, no. 50-51, pp. 9347-9357, 2001.

[16] K. Gupta, S. Sawhney, S. K. Jain, and A. K. Darpe, "Stiffness characteristics of fibre-reinforced composite shaft embedded with shape memory alloy wires," Defence Science Journal, vol. 53, no. 2, pp. 167-173, 2003.

[17] Y. Ren, Q. Dai, R. AN, and Y. Zhu, "Modeling and dynamical behavior of rotating composite shafts with SMA wires," Shock and Vibration, vol. 2014, Article ID 765875, 16 pages, 2014.

[18] K. Murugesan, K. Kalaichelvan, M. P. Jenarthanan, and S. Sornakumar, "Enhancement of vibration characteristics in filament wound FRP composite shafts using nitinol wires," Pigment \& Resin Technology, vol. 47, no. 5, pp. 377-385, 2018.

[19] Y. S. Ren, Q. Y. Dai, and X. Q. Zhang, "Modeling and dynamic analysis of rotating composite shaft," Journal Vibroengineering, vol. 15, no. 4, pp. 1790-1806, 2013.

[20] Y. S. Ren, Q. Y. Dai, and X. Q. Zhang, "Free vibration and stability of a rotating thin-walled composite shaft," Journal of Vibration Engineering, vol. 1, no. 28, pp. 59-66, 2015.

[21] E. A. Armanios and A. M. Badir, "Free vibration analysis of anisotropic thin-walled closed-section beams," AIAA Journal, vol. 33, no. 10, pp. 1905-1910, 1995.

[22] Y. S. Ren and S. S. Sun, "Large amplitude flexural vibration of the orthotropic composite plate embedded with shape memory alloy fibers," Chinese Journal of Aeronautics, vol. 20, no. 5, pp. 415-424, 2007.

[23] L. C. Brinson, "One-dimensional constitutive behavior of shape memory alloys: thermomechanical derivation with non-constant material functions and redefined martensite internal variable," Journal of Intelligent Material Systems and Structures, vol. 4, no. 2, pp. 229-242, 1993.

[24] H. Li and K. Y. Lam, "Frequency characteristics of a thin rotating cylindrical shell using the generalized differential quadrature method," International Journal of Mechanical Sciences, vol. 40, no. 5, pp. 443-459, 1998.

[25] T. Y. Ng, H. Li, and K. Y. Lam, "Generalized differential quadrature for free vibration of rotating composite laminated conical shell with various boundary conditions," International Journal of Mechanical Sciences, vol. 45, no. 3, pp. 567-587, 2003. 